Lingun e Literalura, v. 16, n. 19, p. 51-66, 1991.

\title{
DIDO E A RAZÃO DE SUA MORTE
}

\section{Maria da Gloria Novak}

RLSUMO: Vida, amor e morte da fenícia Diclo. O respeito à memória de Siqueu e a construçấo da Cidade. $\Lambda$ chegada de Enéias e o casamento na gruta; abandono, remorso e morle: o fim. Ora, o novo amor consiste num duplo crime, do qual tem consciência a rainha. Qual é esse dupho crime? Didu mereceu morrer (como pensa)? Não mereceu (como diz o Poela)? Como se explica a sua atitude em face do herơi nos Infernos?

Sem dúvida, as figuras femininas são, na Encida, grandes vítimas: de si mesmas (?), dos Deuses e do clestino dos homens. Amata, Camila e Dido sño as mais bem caracterizadas, quer na vida, quer na morte; e, sendo embura vítimas, nâo se mostram como vítimas passivas.

Anles de chegar a Dido, gostária de focalizar outras personagens femininas da Encidı. Eslas, por via de regra, são vílimas: c vílimas passivas. Sua principal caraclerística é o solrimenlo. Há Irês grandes exceções: Camila, a rainha gucreira, e Dido, a rainha organizadora; e, noulro nível, Amaliı, a rainha "doméslica". Não são pacienles, são agenles: até mesmo na morle, como veremos. Ainda assim, vítimas. Há ainda uma personagem que escaparia ao qualificativo passiva. É Ana, à irmã de Dido.

\section{Primeiramente, o que é a Eneida?}

É um poema de Públio Vergílio Maro (c.70 - 19 a.C.), poela maior da época de Augusio, que na litcralura latina tradicionalmente se conla a partir de 43, ano da morte de Cícero.

Na juventude (em 39, ou seja, provavelmente aos trinla e dois anos), o Poela publicou as Bucólicas, poemas líricos de inspiração pastoril (Omnia uincit Amor X 69). Nos dez anos seguintes, compôs um dos mais belos pocmas do Ocidente, Geórgicas, em que enallece o campo (Labor omnia vicit I 145). E, na última década de sua vida, compôs a epopéia Eneida, sua úllima obra, que cle, aliás, sentindo a aproximação da morte mandou queimar, no que, felizmente para nós, não foi atendido (Fata uiam inmenient III 395; X 113).

A Encida não é só uma epopćia inspirada nas helênicas llíada e Odisséia mas ć a cpopéia romana por excelência: é o poema da romanidade, o poema da 


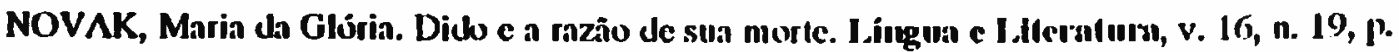
$51-66,1991$.

fundação e da grandeza de Roma, [undação c grandeza delerminadlas pelo Destino. E narra o destino de seu fundador, o troiano Enćias.

Todos conhecemos o roleiro da Eneida, pocma em doze livros.

Nos seis primeiros, encontramos o herói nos mais variados ponlos enlre Tróia c Cartago: sobre o mar e sobre a kerra, c lambém nos sublerrâneos da península ltálica.

Nos seis úllimos, o troiano, já na Península, cnfrenta e vence os obstáculos que se the oferecem à fundação de Romá. São livros de guerra, plenos de episódios de amizade e amor, bravura e insensalcz.

Nos livros I a IV e no livro VI, encontramos, face a lace, os protagonistas do episódio de Dido.

No livro I, o troiano chega, niufrago, às coslas da Líbia, por arles de Juno, sua inimiga e prołctora de Carlago. Juno vê na presença dos troianos ali uma segurança para Dido contra os chefes vizinhos - que cobiçaivaım ao mesmo tempo a cidade e a rainha -, o mais ardente dos quais cra Jarbas, lilho de Júpiler. Mas Vênus, que prolege o fïlho, quer vế-lo na ltália; não conliá numa cidade prolegida por Juno c, com o auxílio do filho Cupido, faz nascer na pobre Dido um amor sem rim pelo herói (cf. 674.749).

No lirro II, esle conta à rainha os úllimos fallos que presenciou em Tróia alé a perda da esposa, o cencontro de sua sombra, c a dilícil decisão de partir. A cidade está prestes a cair às mãos do inimigo. Esle inimigo são os gregos. Todos conhecemos a causa alegada da guerra de Tróia: Helena, esposa do chele grego Menclau, abandona o lar e segue o belíssimo trojano Páris Alexandre, filho de Príamo, o rei. Os gregos, chefiados por Agamenão, irmão do ofendido Menclau, vão à guerra. Cercam a cidade, num cerco lerrível de uma décala. E depois, todos sabemos: o cavalo c ludo o mais. Helena é reconquistada. Volla ao lar c envelhece digna c trancuüilamente.

No livro III, cnfim, Enćias relala a construção dos navios, a partida c a longa viagem. Afastam-se da Frígia e, por sete anos, vagueiam de oráculo $\mathrm{cm}$ oráculo, quer dizer, de déo $\mathrm{em}$ déo, porque os oráculos são dilíceis de entender e de lembrar. Chegam à Sicília, onde o herói perde o pai (708), lålo que nenhum oráculo havia predilo. A essa allura, já conhece o seu destino: a península ltálica - uma terra férlil, chamada Hespéria, onde corre o rio Tibre e onde o esperam uma esposa real e um reino, segundo profetizara a sombra de Creúsa (II 772), primeira esposa, que cle perdera cm Tróia.

O livro IV é tolalmente dedicado à paixão. Selecentos e cinco versos de uma história de amor, herósmo e sacrifício. Amam-se Dido, rainha de Carlago, e Enćias, destinado a ser o fundador de Roma: a rainha esquece a Cidade; o herói esquece a lália. Está cansado de sele anos de incerlezas no mar e se entrega à paz e à segurança de uma cidade erguida, e ao amor. É preciso que o mensageiro de 
NOVAK, Maria da Gilória. Didu e a razîo de sua morle. Liıgua e Lilleratura, v. 16, n. 19, p. $51-65,1991$.

Júpiter o chame à realidade de sua vida e de seu deslino (265-76), deslino que ele próprio aceitara - é por isso que obedece: chorando, abalado o espírito pelo grande amor, como diz o Pocla (332-95.448).

A seguir, no livro $V$, os ventos, um ano após a morte de Anquises, levam os troianos de volla à Sicília. O herói laz realizar jogos fúnebres em honra ao pai (46). As Iroianas, inspiradas por Juno, tenlam incendiar a frota, mas uma chuva limila a perda a quatro navios. Anquises aparece em sonho a Encias e lhe ordena visilá-lo no país das sombras (772), com a Sibila de Cumas. $O$ troiano parte em direção a Continente, acompanhado dos forles, enquanto os fracos permanecem na Ilha e fundam uma cidade. Os que embarcaram alingem seguros a llália mas perdem na Iravessia o seu pilolo Palinuro.

No $V T^{o}$ lìro, chega Enćias à Campânia e procura a Sibila, arauto de Apolo, que prediz as lulas que o herói lerá de enfrentar para conquistar as terras que the reserva o Destino. Enéias e a Sibila descem ao país dos morlos. Alravessam o Cocilo e passam por lodas as regiōes dos Inlernos: pela dos que morreram ao nascer; pela dos inocenles, condenados injustamente; pela dos suicidas que se arrependem do seu gesto (434-7) - e Dido não está entre esses; pela região das vítimas do amor (440 et seqs), onde Enéias encontra Dido e jura que foi contra a vontade que abandonou o litoral da Líbia: tāo contra a vontade como abandonara ílio, mas curvando-se à vonlade do Deslino (cf. II 804 e VI 460: cessi); e chora e tem piedade da rainha, diz o Pocla; passam a seguir pela região dos morlos na guerra - e os soldados de Agamenão logem ao ver o lroiano; encontram aí Deílobo (494), irmão de Páris e terceiro marido de Helena, que a bela entregara aos gregos na última noile; atravessam depois a regiño dos castigos dos criminosos e chegam à dos benleitores da humanidade (637), que esperam o fïp jos seus mil anos de purificação para voltar à lerra. Enlre estes eslá Anquises. O pai mosıra ao filho o futuro de Roma e a grandeza de sua raça (te lina fata docebo, 756 et seqs), destino depois descrito no escudo ficito por Vulcano (cf. VIII 626-728). E o fundador vol ta com a sacerdolisa à superlície da terra.

A partir de então, não mais abandona a Península.

No livro VII, está na embocadura do Tibre (25), no ponto que lhe é destinado e que ele lem de conquislar pelas armas. Aí encontra o rei Latino, a filha desle, Lavínia, noiva do chefe rúlulo, Turno. Oráculos haviam anunciado a chegada do herói (59) e esté é bem recebido por Latino, que nele vê o genro prometido por Fauno, seu anlepassado (249 el seqs). Juno encoleriza-se e, à sua ordem, uma das Fúrias, Alecto, a mais terrível (de cabceça envolta em serpenles), inspira a rainha e Turno contra o troiano (341). Ainda por arle de Alecto, lulo mala uma corça de estimação, e a luta começa (475 el seqs).

No livro VIII, fortalcece-se a confiança de Enćias em si mesmo e no seu fur turo. $O$ arcádio Evandro e o Deus do Tibre ajudam-no a encontrar-se: o herói accitara o seu destino c o Destino deve cumprir-se: fata uiam intenient, dirá Júpiler na assembléia dos Deuses (X 113). É o Deus do Tibre quem o aconselha a 

51-66, 1991.

procurar Evandro, eslabelecido cm Palanlcu (18). Esle mostra-lhe o sílio $\mathrm{cm}$ que se ergucrá Roma (306). Diz-lhe que os etruscos lutarão com ele contra o seu próprio rei, Mezêncio, e contra Turno. Fecha-se o livro com a descrição do escudo de Enćias, forjado por Vulcano e no qual se vê o futuro e a grandeza de Roma.

No lirro $I X$, na ausência de Enéias, que fora buscar a aliança dos etruscos clefiados por Tarco, os rúlulos tentam incendiar os navios troianos, mas cstes se Iransformam em Ninfas (107). Ascánio, o filho do herói, mata o primeiro inimigo c recebc o conselho de Apolo (656) - o mesmo conselho que Ancuises dera ao fitho nos Infernos: evilar a guerra. Os rútulos invadem o campo troiano. Lula-se lerozmente. Os troianos fogem, reagem. E Turno foge.

No livro $X$, assembléia dos Deuses: esles podem alrasar o Destino mas não podem impedir que se cumpra. Os rúlulos alacam (118). Volla Enéias, a quem se aliaram Tarco e os elruscos, lirrenos e lígures (308). Odeia-se, lula-se. Turno mala Palas, fillho de Evandro, o que, ao fim, lhe cuslará a vida. Enéias mata o rei ctrusco, Mezêncio, e o fillho deste, Lauso, episódios dos mais belos e significativos do poema e que, em geral, mais se recomendam à leitura (798 et seqs.833 ct secjs).

No lirro $X I$, honras aos mortos nos dois campos. Evandro recebe o corpo do filho (139). Os latinos querem a paz (296). Turno propōe enfrentar sozinho o rival, mas um ataque troiano interrompe o conselho de guerra (445). Neste livro, a morte de Camila (778 et seqs), figura magistralmente consıtrúda e à qual adiante voltarei.

Enfim, no último livro, XII, Enéias e Lalino concluem o pacto segundo o qual o Iroiano e o rúlulo, em combale singular, decidirão a guerra. Os rúlulos rompem o pacto c o troiano é ferido. Vênus cura o filho. Enéias e Turno devas lam as fileiras; e quando o herói decide invadir a cidade latina, a rainha desespera-se e mata-se. Enfim, o combate singular. Júpiler próibe a esposa, Juno, de vollar a interferir no destino do herói. $O$ troiano vence o rúlulo, recebe a mão de Livínia e aí está, segundo Vergílio, o começo da história de Roma: fata uiam inuenerumt, "os destinos encontraram seu caminho".

Focalizemos as liguras femininas.

Estão a merecer carinhoso estudo as mulheres anônimas da Eneida. Na Sicília, as troianas que tenlam incendiar a frola (V $613 \mathrm{cl} \mathrm{seqs);} \mathrm{na} \mathrm{Península,} \mathrm{mães}$ de Palanteu e mulheres de ílio, a chorar a morle do filho de Evandro (XI 36.146); latinas que maldizem a guerra (215), ou, aflitas, ocupam as torres para ver o combale entre Enéias e Turno (XII 131); ou se cobrem de lulo com Lavínia pela morle de Amala (604-7): vítimas, sempre vílimas; e a mãe de Euríalo, a chorar a perda do filho (IX 284 el seqs.473-502): mãe sem nome próprio, como a representar as mães de lodos os pobres Euríalos sacrificados na insensatez das guerras.

Excetuemos essas grandes vítimas anônimas $\mathbf{c}$ também as Deusas e as semideusas, as Fúrias e a Sibila.

Encontramos primeiro, em Tróia, Cassandra, Hécuba e as noras, Helena, Andromaca c Creúsa. 
NOVAK, Maria dn Glớria. Dido e a razĩo de sua morte. Lingua e Lileralura, v. 16, n.

19, p. $51-66,1991$.

Cassandra aparece uma única vez na Eneida (II 403). Com os cabelos em desordem, a virgem fillha do rei Príamo é arrastada pelos gregos, erguendo inutilmente os olhos ao céu: os olhos, que as mãos as tem presas. A sua imagem é de grande aflição e dor.

Hécuba é a esposa de Príamo: com as cem noras, testemunha o assassínio do marido. A primeira imagem que dela se tem é de pânico, diante da ruína dos muros do palácio (II 486-90). Depois interpela amorosamente o esposo, quando o vê portando armas então inúteis (519-25). Veremos que é sempre amoroso o modo como as esposas se dirigem ao marido: aqui Hécuba, depois Creúsa; na Península, Amalia.

Helena, Enéias a vê senlada à cntrada do templo de Vesta, silenciosa e escondida (ll 567-8), após haver cometido os crimes que o lerceiro esposo, Deílobo, chamando-a egregia coniunx, conla nos Infermos a Enéias (VI 511-30). Vênus é mais indulgente com Helena: diz que não foram nem a delestável beleza da argiva nem a culpa de Páris a causa dos males de ílio, mas a inclemência dos Deuses (1I 601-3).

A Andrômaca, esposa do chefe Heitor, chama-a o Poeta infelix (II 455). Reduzida à escravidão após a queda de ĺlio, chorando inconformada a perda do filho e do esposo, a vida serena em Butroto não the apaga as antigas dores e humilhaçōes (III 294-345).

A mãe de Iulo, Cretisa, a esposa literalmente perdida no tumulto da guerra, presente ao longo de mais de duzentos versos do livro II (562-794), filha dos reis de Tróia, é uma das grandes vítimas no poema. O seu primeiro epíteto é desertı, "abandonada" (II 563). Sua imagem é de dor, submissão e súplica (651 et seqs), amor e bom-senso: abraçada aos pés do marido ante a queda iminente de Tróia, suplica-lhe que a leve com ele à morte ou defenda o lar (hanc primum tutare domem II 677). Desaparece ao abandonar a cidade (738-40), e o herói nunca mais a encontra viva: somenle lhe vê a sombra, Iriste imagem, que o chama dulcis coniunx c lhe profetiza um novo reino e uma esposa real (769-94).

Na Península, vemos Caieta, Sílvia, Lavínia e Amala, e Camila.

Os funerais de C'aieta, a ama, iniciam o livro VII (1-6): é enterrada na costa do Lácio e esse é, simbolicamente (?), o primeiro alo do herói em terra firme.

A Sílvia (VII 92.483 el seqs), filla do pastor do rei, cabe a tristeza de ver assassinado o seu animalzinho de estimação.

A primeira menção de Lavínia, fillha dos reis do Lácio, está no livro VI (760 et seqs), nos Infernos, onde é chamada coniunx. Anquises mostra a Enéias o último filho que lhe dará Lavínia, Sílvio, futuro rei de Alba Longa. Volta, a seguir, nos livros VII, XI e XII. À revelia dos seus, deseja o rei acolher no Lácio o troiano. A virgem Lavínia, causa de lanto mal (causa tanti mali, como diz o Poela, XI 480), é desejada por muitos pretendentes (VII 52-5), o mais ardente dos quais - e falal - é Turno, chefe dos rútulos. Cora dianle do apaixonado Turno e chora à idéia de perdê-lo (XII 64-7); mais tarde, entrega-se à dor ao ter conhecimento da morte violenta da mãe (605-6). 

$51-66,1991$.

Pudor e sofrimento são as suás caraclerísticas; pobre vítima inclefesa por mais que lente prolegê-la a mãc: Turno quer Lavínia, mas Enćiass quer a ltailia. A menina ć condição c o Destino deve cumprir-se.

A história da rainha do Lácio, Amata, de sorke inglória, uma das três lïguras femininas mais lorles e mais bem construídas da Encida, é inlimamenle ligada à da filha. Admira Turno e o quer para genro (VII 56-7): admiração e querer desastrosos, porque o rúlulo não lerá a mão da jovem, c luxlo gira cm torno disso. Amala chora c fala mansinho (357), como falam no pocmá as esposas: c docemente censura o marido, que quer dar a lilha em casamento a um estranho, sem ter piedade quer da filha, quer da esposa, quer de si mesmo. Acusa o troiano de querer roubar-lhes a menina, como Páris roubara Helena (sic). É um discurso longo e inútil. Alormentam-ná inquielações e iras.

Então o veneno que lhe instilara a serpente da cabelcira azulada de Alecto começa a agir, e a inleliz, fora de si, percorre delirante a cidade. (Infelix, diz o Poeta, sine more, lymphata VII 376-7). Esconde a filla nos monles frondosos a a consagra a Baco! E, ao seu exemplo, todas as outras mães sácm de casá transformadas $\mathrm{cm}$ bacantes. A rainha, lendo nas mãos um gallho de pinheiro, canta o hino nupcial para a filha c Turno $\mathrm{c}$ incila as outras mães às orgias bícyuicass (385-403).

Mais larde, alcrrorizada pela sorte da balallaa, chorando, qualse a morrer (conterrita sorte flebat... moritura, diz o Pocta, XII 54 et secps), procura conter o ardor do genro.

Depois, ao julgai-lo morto, perturbada pela dor, clama que cla própria é a causa dos makes e, demente, falando muito no seu Iriste furor, yuase a morrer, diz novamente o Pocta, rasga os mantos de puirpura c, mísera, prende do alto de uma Irave o nó da morte deforme:

Infelix, pugnae iunenem in certamine credit exstiactum et subito, mentem turbata dolore, se causam clamat crimenque capulque malorum, mulhaque per maesfum demens effata furorem purpureos moritura manu discindit amictus et nodum informis leti trabe nectil ab alla (XII 598-60.3).

São cloyüenles os scus epítclos, cloqüente a sua descriçĩo, cloyüente o processo de demência que a domina alé culminar na morte horrenda.

Amata e Dido são as grandes vílimas de Deusass: a peninsular, de Juno; a líria, de Vênus. (Ou serão vítimas de si mesmas, como pensam?) Ambás morrem pelas próprias mãos e, embora decorram ambos os suicídios de um momento de consciência, diferem no cntanto: para Amata, lim; para Dido, como veremos, reinício.

E chegamos a Camila. 
NOVAK, Maria da Glíria. Dick c a razino de sun morle. Lingun e Literatura, v. 16, n. 19, p. $51-65,1991$.

Esła, rainha dos volscos, é guerreira, aspera mirgo na expressño de Vergílio, que a compara ao gavião (IX 664.721-4), uma das duas únicas mulheres verdadeiramente agenles do poema. Consagrada a Diana, a sua história é emocionante. Surge no fim do livro VII (803-17) no desfile das tropas, e o seu surgimenlo ć uma visão de beleza:

"(...) Da naçĩo volsca chegou C'amila chefiando um esquadrão de canaleiros e tropas brilhantes de bronze. Guerreira por excelència, nio habiunara suns mãos femininas ì roca ou aos cestos de Minerva mas a suportar, virgem, duras batalhas e, na corrich, a ultrapassar os ventos. impar; ou roaria por sobre as espigas de uma seara intacta sem ferir; na corrida, as tenras hastes on, pelo meio do mar; deslizando por sobre a onda intumeciden caminharia sem mollarr os ripidos pés.

A guerreira, toda a junentude e as agitadas möes, precipitando-se de casas e campos, atônitas e boqniabertas a admiram e contemplam enquamto passa: o régio manto que vela com pirpura o belo porte; a firela que entrelaça de ouro a cabeleira; ela própria, que porta a aljara lícia e a murta pastoral, guarnecida de ponta de lanģa".

Volla no décimo primeiro livro (498 el seqs.604-7.648 el seqs). Filha de Metabo, a sua história, quem a conta é Diana (XI 535-96).

O pai, cruel rei dos volscos, expulso de seu reino loge por entre lutas de guerra e leva, aperlada ao peito, a tilha pequena, Camila, companheira de exílio. Percorre montes e bosques. Perseguem-no, de lodo lado, selas e, a seu redor, voam os volscos. Eis que, $\mathrm{cm}$ meio à luga, chega a um rio, transbordante por causa das chuvas. Ele, preparando-se para mergulhar, é retido pelo amor à filha e teme pelo fardo que é o objeto de seu amor. A pensar em mil soluções, repentinamente decide. Acomoda a fillha em pedaços de corliça, enrola ludo dem cascas de árvore e equilibra c prende o bebé enroladinho ao meio do darelo enorme e sólido, porque feito de carvalho nodoso, que ele, guerreiro, porlava com mīo forte. Ergue o dardo, balança-o com o bebê preso a cle c reza a Diana:

"Doce virgem fillha de Latona, habitamte dos bostules, a ti en próprio, o pai, dedico esta serva. Portando pela primeira vez as tuas armas, suplicame, atran'és dus brisas foge no inimigo. Recebe com ment testemunho, Densa, como IIII a que agorc é entreguc ìs brisas incertas" (XI 557-60).

Diz. E lançă o dardo.

A menina voa por sobre o rio; o pai altira-se à aigua, escapa aos inimigos e, na oulra margem, arranca do capim o dardo com a garotinha, que é, já então, um dom a Trívia. Nenhuma cidade o recebeu. Viveu nos montes vida de pastor. Alimenlava a filla com o leile de una égua. Quando a menina aprendeu a andar, ar- 
NOVAK, Maria da Glória. Diclu c a razĩo de sua morle. Lingua e Lilerulum, v. 16, n. 19, p. $51-56,1991$.

mou-lhe as mãos com uma lança aguda e pendurouao onbro da pequena $\mathrm{o}$ arco e as tlechas.

3 ?

Camila, diz o Pocta, não leve ouro nos cabelos nem longos vestidos: uma pele de ligre pendia-the da cabeça ao longo das coslas; e sabia girar a funda por sobre a cabeça c abaler o cisne branco. Muilas mães a quiseram por nora, mas a jovem contenta-se com Diana: culliva o amor às armas è̀ virgindiade.

Agora a Deusa lamenta que Camila tenha entrado na guerra, porque os presságios são infauslos. Dá à companheira, Ópis, o arco c a aljava, c lhe ordena vingança: morra aquele que ferir a rainha. Ela mesma levará, numa nuvem, o corpo e as armas da guerreira, para enterrá-los num túmulo na Pálriá. E Ópis desce à lerra.

A seguir, o Poeta mostra-nos, entregue à lula, o esquadrão de Camila. Esta, portando a aljava, ou atira ou, melhor, esparge selas (lenta... spargens hastilia denset, como diz Vergílio, XI 650) ou brande o machado de dois gumes. Ao ombro, $o$ arco de ouro e as armas de Diana. Mesmo quando bate em retirada, volla-se e espalha flechas. Lula cercada de sua guarda de honra: Irês companheiras escolhidas entre as peninsulares. E luta, aspera uirgo, c vence.

Um lígure a desafia a lutar a pé. Camila se deixa enganar: apeia, mas o guerreiro loge a cavalo. A rainha torna a montar, persegue-o, vence-o. Mas outro, inspirado por Jüpiler, incila os companheiros contra a guerreira (XI 725). E outro, Arrunte, decide derrubá-la: segue-a de perto. Camila, de repente - e esse é o seu único erro -, vê Cloreu com a clâmide cor de açalrão, lodo brilhante cm ouro nas suas armas frígias; até o cavalo eslá enfeilado por uma pele de animal enılrelecida de ouro. A visão é excessiva! Guerreira ou gavião, Camila ć mulher. Não vê mais nada: só Cloreu. E assim acaba caindo às mãos de Arrunte, que lança o dardo rezando a Apolo, o mais divino dos Deuses, e pedindo-lhe não troféus ou despojos mas apenas o poder de ferir Camila e vingar a desonra de suas armas (XI 785-93). Logo que o lança, lodos os volscos olham na direção da rainha: ela nem ouve nem vê nem percebe nada. E o dardo lhe penelra tunclo no seio e, como diz o Poela, lhe bebe o sangue (XI 801 et segs).

A guerreira puxa com a mão o dardo mortal, mas este está preso. Comandante, ordena a uma das companheiras que fuja e leve a Turno as últimas ordens: que se entregue à luta è afaste da cidade os troianos. A morrer, a guerreira tem consciência de sua força (pottui XI 823), que ora se exlingue e das trevas que começam a envolvê-la. E diz adeus (iamque uale 827). O Poela faz morrer Camila como viveu: senhora de si, embora vencida:

\author{
(...) Simul his dictis linquebat habenas \\ ad terram non sponte fluens; Ium frigida toto \\ paulatim exsoluit se corpore lentaque colla \\ et captum leto posuit caput arma relinquens \\ uitaque cum gemilu fugit indignata sub umbras (XI 827-31)
}


NOVAK, Maria da Glória. Dictu e a razĩo de sua morte. Liugua e Jlleralura, v. 16, n.

19, p. $51-66,1991$.

"Largava as rédeas enquanto falava escorregando à terra, contra a vonlade; então, fria, pouco a pouco, soltou-se de lodo o corpo e, lenta, apoiou a nuca e a cabeça vencida pela morte, abandonando as armas; e a vida, gemendo, foge indignada para o reino das sombras".

Perdida a rainha, a primeira a fugir é a sua ala; seguem-na os rúlulos (XI 868 el seqs), ao passo que correm à luta os teucros, os tirrenos e os arcádios de Evandro (832-5).

Há vários aspeclos interessantes aqui. Primeiro a identificação de Camila a sua alma e a sua vida, o que, embora seja imagem corrente na poesia clássica, não deixa de ter grande força neste passo. Também a sua indignação e dor ao enfrenlar o caminho das sombras: indignação pelo erro cometido, que a obriga a abandonar o corpo c as armas. E, ainda, a fuga dos seus soldados ao vê-la morta: porque a rainha era o centro da força; ela mesma o dissera (potui XI 823).

Finalmente, em Cartago, fora do roleiro, em perturbador intermezzo, encontramos a grande vílima Dido, que sobressai, como no céu o sol nascente apaga as estrelas, para empregar uma expressão lucreciana; e lambém Ana, a irmã, o Cícero de Dido.

Não lenho a intenção de esludar o comporlamento do herói em relação à rainha, o que liz noutra publicação (C'alíope 7). Parece-me, no entanto, importanlíssimo destacar, na sua vida e em lodos os seus atos, o papel do Destino. Quanto ao mais, o meu inleresse consisle, precipuamente, em esludar a razão da morte de Dido, que, aliás, não pertence ao contexto da fundação de Roma (embora se projele para o fuluro, na ligura do seu vingador, Aníbal).

Sempre me inleressei pelo suicídio da Fenícia, pelo seu amor ao troiano e, principalmente, pelo seu amor a Siqueu e pelo amor de Siqueu, além da morte. Sempre me impressionou vê-la com o marido nos Infernos, o que, afinal, repugna a alguns estudiosos. Sempre me desconcertou o modo como Dido olharia - porque o fato é que não olha - Enéias nos Infernos: torua tuens, que os intérpretes são quase unânimes em Iraduzir por alguma coisa como "olhares furiosos" - e sempre me pareceu que não era isso: e não é. E decidi entender o que não enlendia.

Se o lugar de Elissa é ao lado de Siqueu - é, porque assim o quer o Poeta -, qual a razĩo pela qual pode voltar ao primeiro amor? Como explicarthe a morte? - Cumprimento do destino? Afinal a Encida é uma epopéia e o Destino será a personagem principal. - Castigo? Sempre havia pensado que o suicídio era um castigo. Será um castigo a morte da Fenícia? Por outro lado, mala-se por Enćias? Se não, como explicar que o seu pensamento esteja voltado para ele alć o último suspiro? São as perguntas que me faço.

Primeiramente, quem é Dido?

Em Tiro, é esposa de Siqueu, o mais rico dos fenícios, e o ama com grande amor (I 340-4). Eis o primeiro esboço do retrato: é esposa que ama (uxor amans 
343.352). Siqueu é morto pelo cunhado Pigmalião. Dido loge com o lesouro do marido e os tírios que odeiam Pigmalião. De làto, comannda al luga. Eis o segundo Iraço do retralo: como Camila, é comandante (dur femina ficti l 364).

Em Carlago ć rainha, ća belíssima Diclo, comparável a Diama (1 496-503). Rica e poderosa, dita aos homens o dircilo c as leis cla. a (jecm Jipiter concedeu o fundar uma nova cidade e conler pela jusliça orgullosass naçóes (507-23). Expericnle do mal, socorre os intelizes (630), è à chegalda dos troianos lhes oferece a Cidade:

\section{Voltis et his mecum pariler considere regnis?}

Vrbem quam stafuo uestra est (I 572-3)

"Quereis lambém estabelecer-vos comigo, igualmenle, nestes reinos? A Cidade que ergo é vossa".

Entretanto Vênus, que leme os lenícios (I 861 ) e leme, principalmente, o poder de Juno, inimiga do troiano, imagina para proleger o lïlho novas arles; c decide inflamar na rainha um grande amor, que nenhum poder divino possa mudar: o que faz, na primeira noile, no primeiro bancucece, por meio do lilho Cupido (I $657 \mathrm{et}$ seqs). E aquele coração, que perdera o hábito de amar, é inllamacto de um amor novo e vivo, que suplanta a lidelidade à memoria de Sigucu (719-22).

Assim, a rainha, que vivia como plancjara sua vidal, a belíssimal, qual Diana, a felicíssima Dido, se translorma, sem saber (inscia I 718), na inleliz, na mísera, na nisćrrima Fenícial: "bcbe" um amor sem lim (749), que Deus nenhum pode muklar (674), e se consome num "logo que arde sem se ver" (caecus ignis, diz o Pocta, IV 1-2).

E começa a pensar que, se nĩo houvesse decidido não se unir a ninguém pelos laços conjugais depois que a morle levara o scu primciro amor, se nõo livesse desgosto do lálamo e das lochas nupciais, lalver pudesse sucumbir a essa culpa: só a essa culpa. Reconhece os vestígios da anliga chama: entretanto quer ser devorada pela kerra ou fulminada pelos ráios de Júpiler antes de violar o pudor ou romper juramentos de fidelidade. Siqueu levou o seu amor, diz: que o lenhat e o conserve consigo no sepulero (IV 15-29). Dido quer lutar, e luta. Cupido, na verdade, nem lhe apagou a lembrança de Siqueu nem a consciência da culpa: a consciência permancece lïel. Os sentidos, nĩo mais.

Consulaa a irmañ, que the diz as palavras que os senlidos descjam ouvir (IV 31-54): palavras que mais the inllamam de amor o coraly̧ăo c the dĩo esperançás ao espírito indeciso e lhe cortam os laços áo pudor:

(1) Infelir: I 712 749. IV 529.596. VI 456; misera: I 719.IV 429); misemime IV I17; morilumdar: IV 323; moriturr. IV 308.529.604. 
NOVAK, Maria da Gilória. Dido c a raz:ĩo de sua mortc. Língua e Lilleralura, v. 16, n.

19, p. $51-(6,1991$.

His dictis impenso animum inflammanit amore spemque dedil dubiae menti soluirque pudorem (IV 54-5).

Já não se compara a rainha a Diana mas a uma corça lerida cue dispara pela floresla, fora de si, com o ferro morlal preso a flanco:

\section{Vritur infelix Dido, totaque uagatur}

urbe furens, qualis coniecta cerua sagitha (IV 68 et se(p).

Juno, vendo-lle o solrimento e vendo interrompida a construção da Cidade (IV SS), e revollada porcue a pobre Dido é vílima do luclibrio de duas divindades, propõe a Vênus o cásamento dos heróis:

Quin potius pacem acternam paclosiue hymenacos

exercemus? Habes tola quod mene petisti:

ardet amans Dido traxilque per ossa furorem.

Communem hunc ergo populum paribusque regamus

auspiciis: liceat Phrygio seruire marito

dotalisque fuac Tyrios permillere dextrae (IV 99-104)

"Por que não preferimos uma paz clerna e laços conjugais?

Tens o yite, de lodo o coração, pedisle:

arde uma Dido amante e leva a paixão nos ossos.

Governemos, pois, um só povo, sob os mesmos

auspícios; scja-lla permilido obedecer a um marido frígio

e conliar à lua destra, como dole, os lírios".

Vênus comprecende a intenção, que não ć outra senão alastar Enćias da láilia - mas concorda e sorri (IV 128).

O (que é muito importante observar é que, para Dido, embora não para Enćias (cl. IV 338-9), - e essa ć a razão do sorriso de Vênus - houve casamento: estiveram presentes Juno, a protelora do matrimônio, as Ninfas, as lochas co óler cúmplice das bodas. Mas o herói não os viu. E esse dia foi o primeiro da morle da rainha; esse diá loi a causá dos scus males (166-70).

Diclo se decém a bordar com fïos de ouro os manlos do herói (IV 26.3-4) e invoca a legitimidade da nova uniño para esuuecer a infidelidade à primeira (ct. Guillemain 1968: 242), mas nem a legilimidade de um amor consagrado pelo matrimónio anula á culpa com relação a Siqueu: e essa culpa c o remorso decorrente dominarão mais larde a Dido abandonada por Enćias.

Jarbas, anligo prelendente recusado, reclama ao pai, Júpiler Hamon. Este envia Mercúrio, que interpela o troiano, que, entregue ao amor, esquece a Itailia. E Enćias deve partir. 

51-66, 1991.

A rainha pressente o que está para acontccer: quem pode enganar um coraçĩo que ama (IV 295)? Imedialamente pensá na morle, porque pensa em Siqueu. Mas procura o herói. Invoca o amor, o casamento ${ }^{2}$; chama-lhe perfidus; invoca a morle para dissuadi-lo de partir ${ }^{3}$; invoca o perdido pudor e a fama, e a solidão (305-30). Chora, implora e suplica (413-4). O herói resisle (438-49).

Então a misérrima Dido, alerrorizada pela vergonha c pelá solidão iminenIc, anseia pela morle: vem-lhe o desgosto de ver o céu (IV 450-1). Lembra-se de que não the era permilido viver, sem crime, a vida segundo o costume das feras; lembra-se das promessas feilas às cinzas de Siqueu (550-3). Repudiada, ela mesma sente como paixão adúltera o segundo casamento. Pardida a honra, derrolada pela dor e pelo remorso, decide morrer ${ }^{4}$

Quin morere ut merila es? Ferroque auerte dolorem (IV 547)

"Por que não morres, como mereces? Alásta com o ferro a dor".

É enorme o desejo de voltar ao primeiro amor: ouve o marido a chamá-la; ouve a coruja, com o seu canto fúnebre e o lamento. Sonha com o herói a repelila e se vê sempre sozinha, por um caminho longo, á procurar os lírios na lerra deserta (IV 460-78). Se pudesse apagar o intermezzo troiano!

Felix, heu nimium felix, si litora tantum numquam Dardaniae tetigissent nostra carinae (IV 657-8)

"Feliz, ah!, muitíssimo feliz se, ao menos, as naus dardânias ñ̃o houvessem jamais alingido as nossas praias!"

Tem horror à luz e à vida (IV 692), porque anscia pelo silêncio e pelas sombras que envolvem Siqueu:

Vixi et quem dederat cursum fortuna peregi, el nunc magna mei sub ferras ibil imago (...) Moriemur inullae, Sed moriamur (...) Sic, sic iuuat ire sub umbras (IV 653-4.9-60) "Vivi e percorri o caminho que me dera a fortuna.

E, agora, uma grande imagem minha irá para debaixo da terra. Morreremos sem vingança: morramos porém (...)

(2) Data dertera quondam (IV 307); per conubia nostra, per inceplos hymenacos (310); coniugium mitiguom quod prodidit (Aeneas) 431).

(3) Nec moritura tenct crudeli funere Dido (IV 308)? Cui me moribumdann deseris (...) (323)?

(4) Ergo uli concepti furias euictn dolore decrenitque mori (IV 474-6): entencto concepit furias como "sentir remorso", porque, de falo, o remorso cnfurece, enlonquece. 
Assim, assim quero ser envolta pelas sombras".

Decidida a expiar a culpa (certa mori, como diz Mercúrio, IV 564), ordena os preparativos do sacrifício: o lcilo conjugal ${ }^{5}$, os despojos do amante e as vítimas (636).

A irmã não entende (IV 500-2). Ana jamais, aliás, entendeu o coração de Elissa: pensa na Cidade. Já antes, a uma Dido indecisa dianle da promessa ao marido e indecisa diante do novo amor, racionalizara: primeiro, dizendo que os morlos eslāo bem mortos, o que não é verdade: eles vivem em nós, na lembrança que lemos do amor que livemos; a seguir, dizendo que havia perigo de lodos os lados para Carlago; e, lerceiro, lembrando o quanto podia crescer a glória de Carlago, se Dido livesse o troiano por marido (34-49).

Entim, morre a Fenícia Dido. Convencida de culpa, ergueu o allar do sacrilício e foi a própria vítima expiatória.

Que culpa? - Dupla: contra as promessas feitas a Siqueu c não cumpridas; c contra si mesma, o pudor, a houra, a fama.

Poderíamos imaginá-la culpada cm rclação à Cidade. A rainha, porém, não se vê assim: urbem praeclaram siatui, mea mox'nia nidi (IV 655). Nem a vê assim o Poela: nec fato merita nec morte (696). Dido nõo morreu para cumprir o destino. A Eneida ć uma epopéia: mas o episódio de Dido é um conlo de amor. Também não morreu de morte merecida. Míscra, morreu anles da hora, dominada por um súbito amor (697), do qual não pôde nem poderia jamais livrar-se. Vênus o determinara: amor que Deus nenhum poderia mudar, o que explica o não querer vingar-se do herói, e o que explica o seu pensamento voltado pára ele até o último instante de sua vida.

Ovídio, que alguns estudiosos consideram o menos indicado entre os exegelas de Vergílio, é, ao meu ver, quem mellor entendeu o coração da Fenícia. Escreve em prelensa Ciarta de Didlo a Encéias:

Et quo, si non sim stulta, carere uelim.

Non tamen Aenean, quamuis male cogirat, odi.

Sed queror infidum questaque peius amo (28-30)

"(...) Não fosse cu insensata, quereria passar sem ele;

Enćias, no entanto, embora planeje o mal, não o odeio, mas lamento-o, infiel, c, lamentando-me, pior o amo"

Pensando no pudor e em Siqueu, leria Dido escrito ainda:

Exige, laese pudor, poenam el uiolate Sychaee

Ad quem, me miseram, plena pudoris eo 


\section{(...)}

Da ueniam culpae (97-8.105)

"Exige, pudor ferido, meu casligo, c lambém traído Sicjucu, a quem me dirijo, pobre de mim, cheia de vergonha.

Pcrdoa minhá culpa".

De fato, o que Elissa procura na morle é a companhia de Siqueu. Tanlo que, nos Inlernos, nio eslí entre os que se arrependem de haver procurado a morte. Dido nõo se arrepende; e esla nas planícies que chorám, entre os que o duro amor devorou com seu veneno crucl, c aos quais não abandonam, nem na própria morte, as inquiclaçōes. O que explica a sua altitude ao se deparar, lá, com o herói: inflamada (ardens), nāo o encara; de olhos baixos, ouve-o e, já agora senhora de si, não demonstra qualquer emoção; atinal, sem amor ao troiano (inimica, diz o Pocta), se refugia no bosque onde o primeiro marido, Sicuecu, lhe responde às inquictaçōes e corresponde ao amor (467-74).

Há, ainda, um dado que me parrece inleressante. Se a rainha não se considera culpada em relação à Cidade, e lambém nĩo a consideraria o Poeta, Ana lálvez pense diferentemente:

\section{Exstinxti te meque, soror, populumque palresque \\ Sidonios urbemque Iuam (IV 682-3) \\ "Destruíste a ti e a mim, irmã, o teu povo c os nobres sidônios ca à lua Cidade".}

Ora, Dido ao procurar a morle é a mullher, a cimmente, mas arrasta consigo a rainha. E Ana sofre nalluralmente como irmã de Elissá, mas não sei se não, principalmente lalvez, como irmã da rainha de Carlago; e não sei se não interprela o sentido romano de valorizaçẵo da Páltria. E se Alna é o duplo de Dido, como cm geral se diz, então será o duplo rainhlo, comandante: não amante, mulher, apesar da impressão contrária que pode, às vezes, causar-nos (cli.lV 34 et seqs), o que, ao meu ver, nĩo imporla; nem creio que importasse realmente a Vergílio. Vollo a Ovídio, que lermina a Carta de Dido com eslas palavras:

Nec consumpla rogis inscribar Elissa Sychaei;

Hoc lamen in fumuli marmore carmen erit:

"Praebuil Aencas el causum mortis et ensem;

Ipsa suea Didlo concidit usa mamu"

"Consumida pela pira não terei a inscrição Elissa de Sicune".

Estes versos, porém, se encontrarão no mármore do lúmulo:

Den Enćias tamto a catsa da morte como a csprada.

E Dido cain, tendo usado, ela própria, suta misi". 
NOVAK, Maria di Gilória. Diđu e a razâo de sua morle. Língua e Lilleratura, v. 16, n.

Eis, novamente, a Dido que distribui a justiça. O que me parece fundamenlal é que a morle volunlária de Elissa em holociluslo a Siqueu é um gesto de amor e a leva de volla a cle. Siqueu é o seu Deus: é o amor eslível que Elissa procurou, c não encontrou, no Troiano.

Para tinalizar, gostaria de eslabelecer um paralclo entre Camila e Dido e, mais frouxamenle, Amala, as três rainhas que pagaram com a vida o preço de seu engano. Encyuanto as duas primeiras surgem como personagens agenles e poderosas, Amalta, mais frágil, se resıringe ao âmbito da família.

Camila foi enganada pelo fulgor das armas de Cloreu; Dido, pelas arles de Vênus, pela beleza do herói (os umerosque Deo similis I 589); Amala, pelos seus poderes de esposa e de mãe. Ao fim, absolutamente conscientes de sua vida, indignam-sc por haver crrado: é nítida em Camila a indignação; cm Dido, o remorso que leva à purilicação pelo sacrifício; em Amala o remorso que leva à demência e à morte infame. Enquanto a primeira, indignada, abandona as armas c, gemendo, vai para o reino das sombras, Dido, humilhada e cheia de esperança, procura o primciro amor. A rainha do Lácio, porém, fora de si após breve momento de consciência, procura a morle. (E na mortc? Castigo? Descanso?)

Enfïm, Diana, a quem lora consagrada Camila, dă-lhe sepullura. Siqueu, a quem Dido amara, recebe-a nos Infernos. E Amala? Nem se lhe menciona funeral: sua morle ignóbil não tem as dimenses do sacrifício de Dido ou da morle não procurada de Camila.

O que é preciso assinalar é que o crro ficou - sempre - na vidh. Islo é bem claro no caso de Amala: a última lembrança ć o seu último geslo: lím absoluto. Camila lambém não aparece nos Infernos. Morreu. simplesmente, apesar da bela imagem poćtica do décimo primeiro livro: minaque... firgit... sub umbras (831). Portanto, morreu com ela o descjo das armas de Cloreu, se já não havia morrido anles, como ao meu ver morrera, no momento da consciência. Dido aparece no Aqueronte mas, com relação a Enćias, inimica, "não amiga", islo ć, sem amor. Ou scja, 0 amor verdadeiro, que ć o amor a Siyucu, vence a morle c a acompanha ao mundo das sombras, o que nos leva de volta às Bucólicas: ommin uincil Amor. $O$ ammor paixão, não: o amor que Vênus e Cupido insullaram na pobre Elissai, c que a levou à morle e que Deus nenhum poderia vencer, a morle o venceu.

\section{BIBLIOGRAFIA}

\section{Obras especiais.}

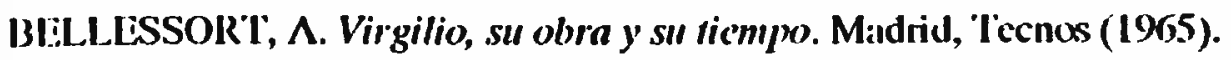

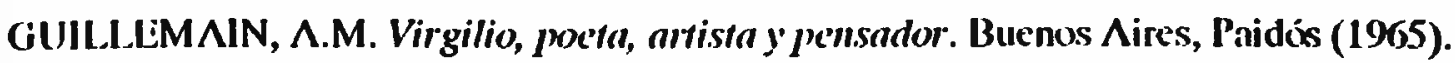

PLiRRET, J. Virgike. (Paris) Du Seuil (1959).

RAT, M. "Introduction". In: VIRGiLE LEncide. Parris, Garnier (1960). 


\section{1. 'Textos.}

OVIDLE. Iléroides. Paris, "L.es Belles Lellres", 1961.

VIRGILE. Encidk. Paris, "Les Belles Lelles", 1966.

RÉSUMtÉ: Didon, sa vie, ses amuurs, sa mort. La rcine, fictìle à la mćmouire de Sychće, bâtil la ville de C'arthage. Cependant, l'arrivée du Troyen a le pouvoir de loul bouleverser el, pour un monnent, la reine abandonne ses promesses de jadis. A-I-clle oublié son premier amour? Comment peul-on expliquer qu'il th reçoive? Enfin, Didon est-elle coupable? Se sent-cille coupuble? Comment doit-on comprendre sa murt? Châtiment? Deslin? Désespouir? Remords?

Les femmes sont de grandes victimes dhns le poùine. Lin quioi Dichon cl deux aulres reines, Camille et Amata, difterent-clles des autres personnages féminins? 